\title{
Neuropsychological assessment of executive functions in traumatic brain injury: hot and cold components
}

\author{
Rochele Paz Fonseca, Nicolle Zimmermann, Charles Cotrena, Caroline Cardoso, Christian Haag \\ Kristensen, and Rodrigo Grassi-Oliveira \\ Pontifícia Universidade Católica do Rio Grande do Sul, Porto Alegre, RS, Brazil
}

\begin{abstract}
The present study compared decision-making processing between patients with traumatic brain injury (TBI) and healthy controls. The study also sought to identify dissociations in the frequency of deficits in executive functions (EF) tasks that mainly assess decision making (DM; hot component) and inhibition (cold component) following TBI. The sample was composed of 16 postTBI adults aged between 18 and 68 years and 16 healthy controls matched by age and education. Decision-making was assessed with the Iowa Gambling Task (IGT), and inhibitory control was assessed with the Trail Making Task (TMT) and Hayling Test. No differences were found between groups in total scores and block scores on the IGT. However, TBI patients preferred the disadvantageous decks, with no evidence of learning during the task. Seven patients presented dissociations between deficient DM on the IGT and accurate inhibition on the Hayling Test and TMT. Conversely, five patients presented partial dissociations between deficits in the IGT and TMT and opposite performance in the Hayling Test. Only three patients exhibited deficits on all of the instruments. These results indicate that patients can maintain comparable performance on the IGT after TBI. Therefore we found dissociations in hot and cold executive components.
\end{abstract}

Keywords: neuropsychological tests; executive function; decision making; inhibition; traumatic brain injury.

Received 14 June 2012; received in revised form 31 October 2012; accepted 14 December 2012. Available online 28 December 2012.

\section{Introduction}

Executive functions (EF) can be considered a complex umbrella process that includes several subcomponents, including initiation, inhibition, cognitive flexibility, shifting, switching, planning, speed of processing, and decision making, that work together to accomplishment goals (Chan, Shum, Toulopoulou, \& Chen, 2008; Verdejo-García \& Bechara, 2010). In neuropsychology, EF has received much attention because of its complexity and multifactorial features, although its nature and the components that integrate this mental function are still controversial (Elliott, 2003; Tirapu-Ustárroz, GarciaMolina, Luna-Lario, Roig-Rovira, \& Pelegrin-Valero, 2008). Some authors have proposed that EF can be divided into "cold" and "hot" processes. Cold components are considered to demand greater use of rationality and logic, such as reasoning, and planning. Hot components are those that involve emotion, such as decision making

Rochele Paz Fonseca, Nicolle Zimmermann, Charles Cotrena, Caroline Cardoso, Christian Haag Kristensen and Rodrigo Grassi-Oliveira, Programa de Pós-Graduação em Psicologia, Faculdade de Psicologia, Pontifícia Universidade Católica do Rio Grande do Sul - PUC-RS. Correspondence regarding this article should be directed to: Rochele Paz Fonseca, Pontifícia Universidade Católica do Rio Grande do Sul - PUC-RS, Av. Ipiranga, 6681, Partenon, Porto Alegre, RS, Brazil. Phone: 55 51 3320-3500 ramal: 7742.E-mail: rochele.fonseca@gmail.com
(DM; Ardila, 2008; Brock, Rimm-Kaufman, Nathanson, \& Grimm, 2009; Chan et al., 2008).

Neuropsychological assessment in individuals with traumatic brain injury (TBI) is a common necessity at all levels of severity of this disorder because cognitive deficits are highly prevalent during its acute and chronic phases (Fork, Bartels, Ebert, Grubich, Synowitz, \& Wallesch, 2005; Zgaljardic \& Temple, 2010). Initially, linguistic and mnemonic assessments predominate because aphasic and amnesic symptoms are more prominent. However, returning to work and daily demands can require more detailed assessments of attention and EF, which are essential for accomplishing tasks (Clune-Ryberg et al., 2011). Neuropsychological assessment and interventions are challenging in individuals with TBI because they are influenced by emotional and psychiatric characteristics that can be present either before or after the injury (Taylor, Kreutzer, Demm, \& Meade, 2010). Assessing the various facets of EF is relevant for rehabilitation (Milders, Ietswaart, Crawford, \& Currie, 2008), but very little is known about hot and cold EF in this clinical population.

Among EFs, DM processes have been studied in neurological patients, including TBI patients, and psychiatric patients, such as substance abusers (Bechara \& Damásio, 2002). Decision-making has been considered a hot EF that involves emotional processing (Bechara, Tranel, Damásio, \& Damásio, 1996; Chan et al., 2008; 
Happaney, Zelazo, \& Stuss, 2004). Neuropsychological research has investigated DM processing based on the somatic marker hypothesis (Damásio, 1996). This theory proposes that when a person needs to make a decision, he experiences somatic sensations (i.e., somatic markers) that occur in advance of real consequences of possible different alternatives. Those implicit markers act as emotional biocatalysts of DM, in which distinct alternatives are evaluated emotionally, based on somatic sensations that guide adaptive DM (Damásio, 1996). The ventromedial prefrontal cortex and its limbic system connections are considered key structures in the DM process (Bechara et al., 1996). The Iowa Gambling Task (IGT; Bechara, Damásio, Damásio, \& Anderson, 1994; Bechara, 2007) is one of the most valued instruments internationally for measuring emotion-based DM (Bowman, Evans, \& Turnbull, 2005).

Studies on DM in neurological populations have been conducted. The IGT has been considered sensitive to aspects of executive dysfunction after TBI (Bonatti et al., 2008; Hanten et al., 2006; Levine, Black, Cheung, Campbell, O'Toole, \& Schwartz, 2005; MacPherson, Phillips, Della Sala, \& Cantagallo, 2009; Wiederkehr, Barat, Dehail, de Seze, Lozes-Boudillon, \& Giroire, 2005).

Another executive component that is frequently impaired in TBI patients compared with healthy controls is inhibition (Dimoska-Di Marco, McDonald, Kelly, Tate, \& Johnstone, 2011; Felmingham, Baguley, \& Green, 2004; Perlstein, Larson, Dotson, \& Kelly, 2006; Larson, Kaufman, Schmalfuss, \& Perlstein, 2007). Inhibition is an important executive ability that allows the individual to suppress, interrupt, or delay a usual or automatic behavior in favor of more complex and controlled processing (Aron, Robbins, \& Poldrack, 2004). Studies suggest that TBI patients can present impairment in this EF (Rao \& Lyketsos, 2000; Dimoska-Di Marco et al., 2011). The literature indicates that some neuropsychological tools, such as bipartite paradigms, are recognized for their ability to accurately assess inhibition because they usually require more automatic processes during the initial phase of assessment. During later phases, a similar paradigm is used with some differences, requiring more controlled processing. The Trail Making Test (TMT; War Department, 1944; Sánchez-Cubillo et al., 2009) and Hayling Test (Burgess \& Shallice, 1997; Chan et al., 2008) are frequently administered for such a purpose. Draper \& Ponsford (2008) studied 60 TBI patients who presented impaired performance on the Hayling Test compared with controls. Periàñez et al. (2007) administered the TMT to evaluate inhibitory control, and they also observed lower performance in TBI patients compared with healthy controls. This evidence suggests that these tests are useful for diagnosing impaired inhibition in TBI patients.

The few studies that have investigated DM and cold EF components in TBI patients have suggested a synergic impaired profile (Levine et al., 2005; Bonatti et al., 2008; Sigurdardottir, Jerstad, Andelic, Roe, \& Schanke, 2010). Bonatti et al. (2008) assessed acute
TBI patients and healthy controls using the IGT, the TMT, and a Go-No-Go task, among other paradigms. Impairments in both inhibitory control and DM were found in TBI patients compared with controls. Levine et al. (2005) performed a study with 71 TBI patients who were assessed using the IGT and TMT and exhibited impaired performance on both instruments. Although these studies investigated both DM and inhibition components, to our knowledge, no studies have assessed $\mathrm{DM}$ and verbal and visuospatial inhibition using, for example, a paradigm like the Hayling Test.

Because the relationships between hot and cold $\mathrm{EF}$, specifically between predominant verbal and visual inhibition and DM, have not been investigated postTBI, the present study compared performance on the IGT between TBI patients and healthy controls. We also verified the frequency of inhibition and DM deficits, seeking to determine possible dissociations between these EF components.

\section{Methods \\ Participants}

Eighteen adults (12 men and four women), aged 18 to 68 years, who had suffered a closed TBI were recruited through outpatient records from hospitals in Porto Alegre, Rio Grande do Sul, Brazil. Participants were included in the study if they did not present moderate to severe aphasia, did not have less than 2 years of formal education, and did not have previous neurological or noncorrected sensorial disorders. All of the patients were native Brazilian Portuguese speakers. Two participants were excluded because they did not complete the battery of tests, resulting in a final sample of 16 TBI patients. A previous history of the presence or absence of psychiatric disorders was not considered an exclusion criterion but instead was characterized as present or absent based on a clinical interview. The sociocultural, individual, and clinical characteristics of the clinical group are presented in Table 1. Neuropsychological assessment was performed at least 1 month post-injury, and the time post-TBI varied from 1 to 50 months.

The control group consisted of 16 non-braindamaged adults who were matched by age and education. A $t$-test indicated that the groups did not differ from each other with regard to age $(p=.370)$ and years of education $(p=.166)$. A convenience sample of adults was recruited from workplaces and community centers. The inclusion criteria for the control group included the absence of a history of psychiatric or neurological disorders, the absence of non-corrected sensorial deficits, and the non-usage of anticonvulsive, antipsychotic, and benzodiazepine medications.

All of the data presented in Table 1 were obtained by means of self-report through a sociocultural and medical history questionnaire (Fonseca, Oliveira, Gindri, Zimmermann, \& Reppold, 2012). More specifically, this questionnaire included questions about gender, age, education, socioeconomic status, frequency of reading and 
Table 1. Demographic and clinical data of the TBI and control groups

\begin{tabular}{|c|c|c|c|c|c|}
\hline \multirow{2}{*}{\multicolumn{2}{|c|}{ Variables/Groups }} & \multicolumn{2}{|c|}{ TBI group } & \multicolumn{2}{|c|}{ Control group } \\
\hline & & $M$ & $S D$ & $M$ & $S D$ \\
\hline \multirow{12}{*}{ 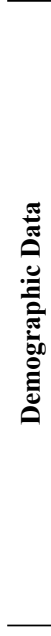 } & Age (years) & 37.31 & 13.65 & 32.88 & 13.09 \\
\hline & Education (years) & 10.50 & 3.48 & 12.44 & 4.2 \\
\hline & Reading and writing habits & 7.94 & 5.15 & 14.25 & 4.52 \\
\hline & Socioeconomic score & 23.44 & 6.87 & 26.63 & 4.89 \\
\hline & & \multicolumn{4}{|c|}{ Frequency } \\
\hline & & \multicolumn{2}{|c|}{$n(\%)$} & \multicolumn{2}{|c|}{$n(\%)$} \\
\hline & Sex & & & & \\
\hline & Male & \multicolumn{2}{|c|}{$12(75.0)$} & \multicolumn{2}{|c|}{$9(56.3)$} \\
\hline & Female & \multicolumn{2}{|c|}{$4(25.0)$} & \multicolumn{2}{|c|}{$7(43.8)$} \\
\hline & Handedness & & & & \\
\hline & Right & \multicolumn{2}{|c|}{$13(81.3)$} & \multicolumn{2}{|c|}{$16(100.0)$} \\
\hline & Left & \multicolumn{2}{|c|}{$3(18.8)$} & \multicolumn{2}{|c|}{ - } \\
\hline \multirow{16}{*}{ 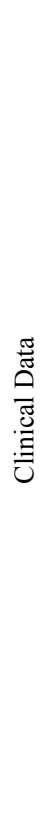 } & & $M$ & $S D$ & $M$ & $S D$ \\
\hline & MMSE & 24.3 & 3.82 & 28.87 & 1.36 \\
\hline & & \multicolumn{4}{|c|}{ Frequency } \\
\hline & & \multicolumn{2}{|c|}{$n(\%)$} & \multicolumn{2}{|c|}{$n(\%)$} \\
\hline & \multicolumn{5}{|l|}{ Severity } \\
\hline & Mild & \multicolumn{2}{|c|}{$6(37.5)$} & \multicolumn{2}{|c|}{-} \\
\hline & Severe & \multicolumn{2}{|c|}{$10(62.5)$} & \multicolumn{2}{|c|}{ - } \\
\hline & \multicolumn{5}{|l|}{ Cause of injury } \\
\hline & Motor vehicle & \multicolumn{2}{|c|}{$8(50.0)$} & \multicolumn{2}{|c|}{-} \\
\hline & Fall & \multicolumn{2}{|c|}{$5(31.25)$} & \multicolumn{2}{|c|}{ - } \\
\hline & Sports & \multicolumn{2}{|c|}{$1(6.25)$} & \multicolumn{2}{|c|}{-} \\
\hline & Others & & & & \\
\hline & Not specified & & & & \\
\hline & Previous psychiatric disord & & & & \\
\hline & Absence & & & & \\
\hline & Presence & & & & \\
\hline
\end{tabular}

MMSE, Mini Mental State Examination.

writing habits, and handedness. The frequency of reading and writing habits was ranked from 0 ("I never read") to 4 ("I read everyday") for books, magazines, and so on, with a maximum score of 16, and from 0 ("I never write") to 4 ("I write every day") for letters, messages, and so on, with a maximum score of 12 (Pawlowsky, Remor, Parente, Salles, Fonseca, \& Bandeira, 2012). Additionally, handedness was verified by means of the adapted Edinburgh Inventory with a maximum score of 20 .

\section{Procedures and instruments}

All of the participants were assessed in a clinical setting in silent and ventilated rooms. They signed consent forms approved by the Ethics Committee of the university (protocol no. 10/05143 and 1679-09). They were assessed in two different randomized orders using the following neuropsychological instruments:
Iowa Gambling Task (Bechara et al., 1994; Bechara, 2007). A computer-based IGT version adapted to the southern Brazilian population by Schneider \& Parente (2006) was used. This version of the IGT showed evidence of reliability in a Brazilian sample (Cardoso, Carvalho, Contrena, Schneider-Bakos, Kristensen, \& Fonseca, 2010). In the IGT, the examinee chooses cards from four decks (A, B, C, and D) in 100 trials. Each card results in either a gain or loss of money. From the four decks, two are advantageous ( $C$ and $D)$, resulting in money gained with low monetary loss during the trial. The other two decks (A and B) are disadvantageous, resulting in short-term greater gains but more frequent losses. The task emphasizes the learning of reward and punishment associations and is an international reference for DM assessment (Bechara et al., 1994; Schneider-Bakos, Denburg, Fonseca, \& Parente, 2010). 
The main dependent variables derived from the IGT are total score and net score $([C+D]-[A+B])$ and block score $([C+D]-[A+B])$ for each segment or block of 20 cards, frequency of deck choices, and spared or impaired performance according to a cut-off point of -10 (established by Bechara, Damasio, \& Damasio, 2000) especially in brain-damaged subjects.

Trail Making Test (War Department, 1944). This instrument consists of two parts. In Part A, the participants must connect numbers randomly distributed on an A4 sheet of paper. In Part B, numbers and letters are to be alternately connected, and they are also distributed in a random order on an A4 sheet of paper. The number of correct answers and errors are considered, such that the maximum number of correct answers is 24 , with no maximum number of errors. The time necessary to complete each part and the relationship between the time necessary to complete Parts B and A are also analyzed. In this task, planning and processing speed components related to visual, perceptual, and motor skills (Parts A and B) and inhibition and switching (Part B) are assessed.

Hayling Test (Burgess \& Shallice, 1997; adapted by Fonseca et al., 2010). This task consists of phrases in which the last word is missing. The participants must complete it with a word that properly fits the sentence (Part A; completing the sentence normally) and with an unrelated word (Part B). Time and accuracy are measured, with a maximum of 15 for quantitative scoring and a maximum of 45 for quantitative-qualitative errors on Part B. Initiation (Part A), verbal inhibition (Part B), and processing speed (i.e., both parts and relationship between time for Part B and Part A) components are assessed.

\section{Statistical analysis}

All of the descriptive and inferential analyses were performed using the Statistical Package for the Social Sciences (SPSS 17.0). A normal distribution was observed in both groups according to the Kolmogorov-Smirnov Test. Mean comparisons between the TBI and control groups were conducted using an independent samples $t$-test for the DM variables (i.e., IGT total and block scores) and inhibition variables (i.e., Hayling Test and Trail Making Test accuracy and time). To compare performance in each block of the IGT between groups during the five segments, a mixed analysis of variance (ANOVA) was performed. To investigate possible dissociations between the occurrence of deficits in DM and other cold EFs, the Z score was calculated for the variables in the Hayling Test and Trail Making Test. The participants were also classified on the IGT as having non-impaired or impaired DM abilities based on the cut-off scores established by Bechara, Damasio, \& Damasio (2000).

\section{Results}

No difference was found in IGT total score $(p=$ .638 ; $t$-test $)$ between the TBI group $(\mathrm{M}=-6.88, \mathrm{SD}=$
11.95) and control group $(\mathrm{M}=-3.50, \mathrm{SD}=25.67)$. A high standard deviation was observed in both groups, mainly in controls, which might reflect the heterogeneity of the sample. The groups were also compared with regard to their performance in each block of 20 cards (Table 2). Figure 1 shows the learning curve of each group.

Table 2 shows no significant differences when each block was analyzed separately. Additionally, the data presented in Figure 1 show no differences between groups with regard to their performance during the IGT blocks ( $p=.446$; mixed ANOVA). Figure 2 presents the frequency of group preferences for each of the four decks (A, B, C, or D). Such an analysis determines whether the most risky decks (A and B) or advantageous decks $(\mathrm{C}$ and $\mathrm{D})$ were chosen.

Figure 2 suggests that the TBI group chose more risky decks ( $\mathrm{A}$ and $\mathrm{B})$, whereas controls more frequently preferred cards from decks B and D. A significant difference was found between groups in deck A $(p<$ .001 ), with TBI patients choosing this risky deck more frequently ( $t$-test). Table 3 shows the groups' inhibition task performance.

in measures of processing speed related to the inhibitory process (time in Part B minus time in Part A of the Hayling Test), in which TBI patients were slower than controls. The errors variable of the TMT, Part B, was significantly different between groups, with inferior performance in TBI patients.

When analyzed together, the $\mathrm{Z}$ scores of deficits in tasks of hot and cold EF showed that seven patients presented dissociations in performance on the IGT (i.e., deficits) and normal performance on the TMT and Hayling Test. Five subjects presented deficient performance on the IGT and TMT and normal performance on the Hayling Test. The greater frequency of patients with impaired DM may be associated with a greater frequency of severe TBI patients in the clinical group; therefore, an additional analysis was conducted. No differences were found between mild and severe subgroups of TBI patients with regard to the frequency of deficits on the IGT, Hayling Test, and TMT (Fisher's Exact Test, $p>.05)$.

Table 2. Performance of each group in Iowa Gambling Task blocks

\begin{tabular}{llrcc}
\hline & & \multicolumn{1}{c}{$\boldsymbol{M}(\boldsymbol{S D})$} & $\boldsymbol{t}$ & $\boldsymbol{p}$ value \\
\cline { 3 - 5 } Block 1 & TBI & $-3.63(5.62)$ & -.227 & .82 \\
& Controls & $-3.13(6.81)$ & & \\
Block 2 & TBI & $.38(6.24)$ & -.056 & .95 \\
& Controls & $.50(6.42)$ & & \\
Block 3 & TBI & $-.50(3.05)$ & -.640 & .53 \\
& Controls & $1.13(9.68)$ & & \\
Block 4 & TBI & $0.00(3.09)$ & .984 & .33 \\
& Controls & $-2.88(11.26)$ & & \\
Block 5 & TBI & $-1.13(3.79)$ & -.863 & .39 \\
& Controls & $.88(8.45)$ & & \\
\hline
\end{tabular}




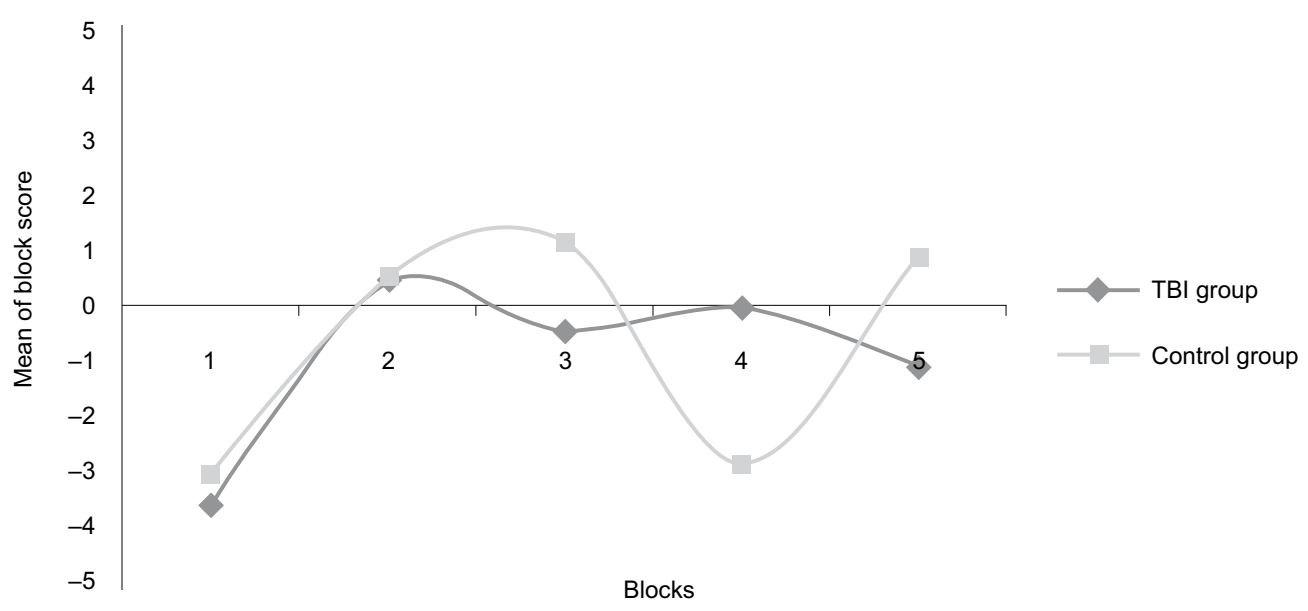

Figure 1. Group performance during the blocks on the Iowa Gambling Task.

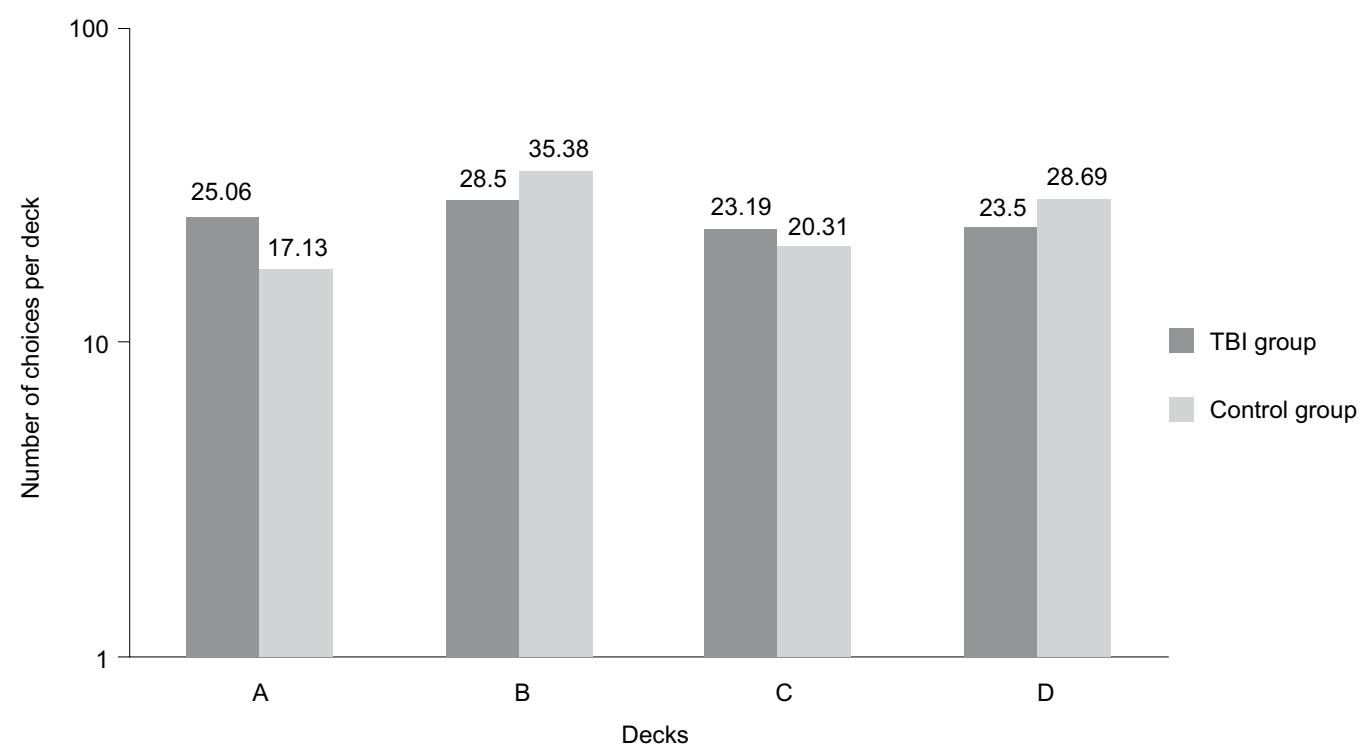

Figure 2. Group preferences for each of the four decks in the Iowa Gambling Task.

\section{Discussion}

The present results suggest that the TBI patients' global performance on the IGT, as a group, did not differ from DM processing in healthy controls. Although no difference was found in the block score, a greater peak of learning was observed in healthy controls. Despite the fact that the control group changed its performance in Block 4, these participants may have preferred more risky cards, looking to gain more money during this segment of the task. In the TBI group, observing a learning curve was not possible during the task, but a constant curve was observed from Block 2 to Block 5. Conversely, in a previous study, healthy individuals initiated the selection of advantageous decks from 30 cards onward, whereas clinical samples generally showed an inability to choose advantageous decks (Dunn, Dalgleish, \& Lawrence, 2006). In the present study, TBI patients preferred disadvantageous decks (A and $\mathrm{B}$ ), followed by a significant difference between groups in deck A.
When interpreted together, these findings suggest that despite nonsignificant differences between groups in total score, TBI patients presented more risk-taking behavior. Van Noordt \& Good (2011) also did not find differences between controls and mild TBI patients on self-reports. However, injury severity was inversely related to DM performance, such that as injury status increased, the quality of this EF processing decreased. These authors pointed out the great heterogeneity of cognitive deficits after mild TBI. In this context, such findings can partially explain the results of the present study with regard to the absence of significant differences between groups in total and block scores. Nevertheless, we highlight the preference of the TBI group for the disadvantageous deck (A), which might be associated with the prevalence of $62.5 \%$ of severe TBI in the sample.

Our findings are generally corroborated by other investigations that evaluated DM in TBI patients using the IGT, in which impaired performance was found 
Table 3. Performance of groups in TMT and Hayling Test

\begin{tabular}{|c|c|c|c|c|c|c|}
\hline & Tasks/variables & Groups & $M$ & $S D$ & $\boldsymbol{F}$ & $p$ \\
\hline \multirow{14}{*}{ 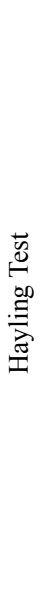 } & \multirow[t]{2}{*}{ Time B/time A } & TBI & 4.42 & 4.08 & \multirow{2}{*}{3.120} & \multirow{2}{*}{.099} \\
\hline & & Controls & 2.64 & .93 & & \\
\hline & \multirow[t]{2}{*}{ Qualitative errors Part B (/45) } & TBI & 19.00 & 10.18 & \multirow{2}{*}{.249} & \multirow{2}{*}{.054} \\
\hline & & Controls & 12.19 & 8.98 & & \\
\hline & \multirow[t]{2}{*}{ Correct answers Part A (/15) } & TBI & 14.69 & .60 & \multirow{2}{*}{.789} & \multirow{2}{*}{.741} \\
\hline & & Controls & 14.75 & .45 & & \\
\hline & \multirow[t]{2}{*}{ Errors Part A (/15) } & TBI & .31 & .60 & \multirow{2}{*}{2.248} & \multirow{2}{*}{.495} \\
\hline & & Controls & .19 & .40 & & \\
\hline & \multirow[t]{2}{*}{ Correct answers Part B (/15) } & TBI & 7.44 & 3.18 & \multirow{2}{*}{.011} & \multirow{2}{*}{.088} \\
\hline & & Controls & 9.60 & 3.64 & & \\
\hline & \multirow[t]{2}{*}{ Errors Part B (/15) } & TBI & 7.88 & 3.05 & \multirow{2}{*}{.158} & \multirow{2}{*}{.067} \\
\hline & & Controls & 5.63 & 3.63 & & \\
\hline & \multirow[t]{2}{*}{ Time Part B - Time Part A } & TBI & 61.93 & 52.16 & \multirow{2}{*}{6.531} & \multirow{2}{*}{.018} \\
\hline & & Controls & 26.22 & 17.98 & & \\
\hline \multirow{10}{*}{ 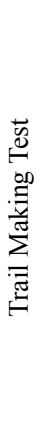 } & \multirow[t]{2}{*}{ Errors Part A } & TBI & .13 & .34 & \multirow{2}{*}{1.454} & \multirow{2}{*}{.559} \\
\hline & & Controls & 0.06 & .25 & & \\
\hline & \multirow[t]{2}{*}{ Correct answers Part B (/24) } & TBI & 22.69 & 3.11 & \multirow{2}{*}{15.026} & \multirow{2}{*}{.112} \\
\hline & & Controls & 24.00 & 0.00 & & \\
\hline & \multirow[t]{2}{*}{ Time Part B - Time Part A / Time Part A } & TBI & 2.00 & 1.66 & \multirow{2}{*}{.813} & \multirow{2}{*}{.457} \\
\hline & & Controls & 1.56 & 1.50 & & \\
\hline & \multirow[t]{2}{*}{ Time Part B / Time Part A } & TBI & 3.26 & 1.66 & 1.843 & 218 \\
\hline & & Controls & 2.56 & 1.50 & & 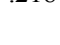 \\
\hline & Errors Part B & TBI & 3.63 & 4.43 & 19980 & 017 \\
\hline & & Controls & .63 & .81 & 17.900 & . \\
\hline
\end{tabular}

compared with controls (García-Molina, Roig-Rovira, Enseñat-Cantallops, Sánchez-Carrión, Pico-Azanza, \& Pena-Casanova, 2007). In these studies, TBI patients failed to learn during five blocks of the IGT. These data characterize a failure in DM processing based on the somatic marker hypothesis assessed by the task (Bonatti et al., 2008; Sigurdardottir et al., 2010). Figure 1 shows that the TBI group did not present typical learning, although no significant differences were found in the mixed ANOVA. This might be attributable to the groups' sample sizes. With the exception of one TBI patient, other patients were impaired in the task. This finding is consistent with previous studies (Levine et al., 2005; Sigurdardottir et al., 2010). We hypothesize that dissociations may exist between groups, depending on the severity of trauma and sample size.

In studies that controlled the lesion site in TBI, performance appeared to be influenced by lesions that affected neural circuitry involved in DM processing. However, recent investigations indicated that lesions that do not involve the prefrontal ventromedial cortex (MacPherson et al., 2009) or frontal cortex (Levine et al., 2005) are associated with impaired performance on this instrument. Our sample was composed of four patients with lesions exclusively in the frontal lobes and other areas, four patients with lesions exclusively in the frontal lobe, four patients with lesions in other brain areas, and four patients with no diagnosed brain damage.
Therefore, although not a direct aim of this study, our findings suggest that even with a reduced sample of 16 patients, a tendency toward deficits was observed in the TBI group compared with healthy controls, independent of the lesion site. These studies suggest that our results might not be specifically related to frontal damage.

Dissociations between deficits have important implications for both theoretical and clinical fields. The first dissociation (i.e., patients had impaired performance on the IGT and normal performance on the TMT and Hayling Test) might be explained in terms of distinct hot and cold components of EF. The dissociation between the two inhibition assessment tasks may be explained by dissociations between verbal and non-verbal inhibitory ability, which require different demands on the executive system. Three patients presented deficits in all of the tasks in the present study, showing impaired hot and cold EF. This may be explained by previous studies that found associations between DM and inhibitory control deficits assessed by both the IGT and TMT (Bonatti et al., 2008; Levine et al., 2005) and studies of inhibitory control that assessed verbal and non-verbal inputs using the Hayling Test (Draper \& Ponsford, 2008) and TMT (Periàñez et al., 2007), respectively. Only one mild TBI patient did not present deficits in any task. We emphasize the heterogeneity of mild TBI neuropsychological deficits (37.5\% of our sample). Our results are generally consistent with studies that showed 
distinct impairments in EF in TBI patients (Dimoska-Di Marco et al., 2011; Felmingham et al., 2004; Perlstein et al., 2006; Larson et al., 2007).

In addition to the known heterogeneity of TBI patients, another limitation of the present study should be considered. Five patients had a previous history of psychiatric disorders that were not specified in the general self-report questionnaire. Numerous studies have shown that psychiatric disorders pre-TBI are prevalent (e.g., Whelan-Goodinson, Ponsford, Johnston, \& Grant, 2009). In studies with larger samples, this factor should be more controlled or further investigated.

The present comparative study between TBI and control groups can contribute to a better understanding of the relationships among different hot and cold EF components post-TBI. Our findings contribute to the notion that hot and cold EF may be associated or dissociated in some TBI patients. This is possibly attributable to the marked heterogeneity of the sample. The interpretation of these initial findings should consider some caveats such as the small sample size and heterogeneity of the clinical sample. Future studies should conduct cluster or comparative analyses, including stratified samples of TBI patients with regard to lesion site, severity, psychiatric profile, medication use, and measures of functionality. With a larger sample size, regression analysis could also be conducted, followed by traditional and relevant neuropsychological analyses of the frequency of deficits. Comprehending cognitive dissociations is one of the main goals of clinical and cognitive neuropsychology.

\section{References}

Ardila, A. (2008). On the evolutionary origins of executive functions. Brain and Cognition, 68, 92-99.

Aron, A.R., Robbins, T.W., \& Poldrack, R.A. (2004). Inhibition and the right inferior frontal cortex. Trends in Cognitive Sciences, 8(4), 170-177.

Bechara, A. (2007). Iowa Gambling Task: professional manual. Odessa, FL: Psychological Assessment Resources.

Bechara, A., \& Damásio, H. (2002). Decision-making and addiction (part I): impaired activation of somatic states in substance dependent individuals when pondering decisions with negative future consequences. Neuropsychologia, 40(10), 1675-1689.

Bechara, A., Damásio, A.R., Damásio, H., \& Anderson, S.S. (1994). Insensitivity to future consequences following damage to human prefrontal cortex. Cognition, 50, 7-15.

Bechara, A., Damasio, H., \& Damasio, A.R. (2000). Emotion, decision making and the orbitofrontal cortex. Cerebral Cortex, 10, 295-307.

Bechara, A., Tranel, D., Damásio, H., \& Damasio, A.R. (1996). Failure to respond autonomically to anticipated future outcomes following damage to prefrontal cortex. Cerebral Cortex, 6(2), 215-225.

Bonatti, E., Zamarian, L., Wagner, M., Benke, T., Hollosi, P., Strubreither, W., \& Delaser, M. (2008). Making decisions and advising decisions in traumatic brain injury. Cognitive Behavioral Neurology, 21(3), 164-175.

Bowman, C.H., Evans, C.E., \& Turnbull, O.H. (2005). Artificial time constraints on the Iowa Gambling Task: the effects on behavioural performance and subjective experience. Brain and Cognition, 57(1), 21-25.

Brock, L.L., Rimm-Kaufman, S.E., Nathanson, L., \& Grimm, K.J. (2009). The contributions of "hot" and "cool" executive function to children's academic achievement, learning-related behaviors, and engagement in kindergarten. Early Childhood Research Quarterly, 24, 337-349.

Burgess, P.W., \& Shallice, T. (1997). The Hayling and Brixton tests. Bury St. Edmunds: Thames Valley Test Company.
Cardoso, O.C., Carvalho, J.C.N., Cotrena, C., Schneider-Bakos, D.G., Kristensen, H.C., \& Fonseca, R.P. (2010). Estudo de fidedignidade do instrumento neuropsicológico Iowa Gambling Task. Jornal Brasileiro de Psiquiatria, 59(4), 279-285.

Chan, R.C.K., Shum, D., Toulopoulou, T., \& Chen, E.Y.H. (2008). Assessment of executive functions: review of instruments and identification of critical issues. Archives of Clinical Neuropsychology, 23(2), 201-216.

Clune-Ryberg, M., Blanco-Campal, A., Carton, S., Pender, N., O'Brien, D., Phillips, J., ... Burke, T. (2011). The contribution of retrospective memory, attention and executive functions to the prospective and retrospective components of prospective memory following TBI. Brain Injury, 25(9), 819-831.

Damásio, A. (1996). O Erro de Descartes: emoção, razão e o cérebro humano. São Paulo: Companhia das Letras.

Dimoska-Di Marco, A., McDonald, S., Kelly, M., Tate, R., \& Johnstone, S. (2011). A meta-analysis of response inhibition and Stroop interference control deficits in adults with traumatic brain injury (TBI). Journal of Clinical and Experimental Neuropsychology, 33(4), 471-485.

Draper, K., \& Ponsford, J. (2008). Cognitive functioning ten years following traumatic brain injury and rehabilitation. Neuropsychology, 22(5), 618-625.

Dunn, B.D., Dalgleish, T., \& Lawrence, A.D. (2006). The somatic marker hypothesis: A critical evaluation. Neuroscience and Biobehavioral Reviews, 30, 239-271.

Elliott, R. (2003). Executive functions and their disorders. British Medical Bulletin, 65, 49-59.

Felmingham, K.L., Baguley, I.J., \& Green, A.M. (2004). Effects of diffuse axonal injury onspeed of information processing following severe traumatic brain injury. Neuropsychology, 18(3), 564-571.

Fonseca, R.P., Oliveira, C., Gindri, G., Zimmermann, N., \& Reppold, C. (2010). Teste Hayling: um instrumento de avaliação de componentes das funções executivas. In C. Hutz (Ed.), Avaliação psicológica e neuropsicológica de crianças e adolescentes (pp. 337-364). São Paulo: Casa do Psicólogo.

Fork, M., Bartels, C., Ebert, A.D., Grubich, C. Synowitz, H., \& Wallesch, C.W. (2005). Neuropsychological sequelae of diffuse traumatic brain injury. Brain Injury, 19(2), 101-108.

García-Molina, A., Roig-Rovira, T., Enseñat-Cantallops, A., SánchezCarrión, R., Pico-Azanza, N., \& Pena-Casanova, J. (2007). Examination of decision-making processes in patients with traumatic brain injury. Neurología, 22, 206-212.

Hanten, G., Scheibel, R.S., Li, X., Oomer, I., Stallings-Roberson, G., Hunter, J.V., \& Levin, H.S. (2006). Decision making after traumatic brain injury in children: a preliminary study. Neurocase, 12, 247-251.

Happaney, K., Zelazo, P.D., \& Stuss, D.T. (2004). Development of orbitofrontal function: current themes and future directions. Brain and Cognition, 55, 1-10.

Larson, M.J., Kaufman, D.A., Schmalfuss, I.M., \& Perlstein, W.M. (2007). Performance monitoring, error processing, and evaluative control following severe TBI. Journal of the International Neuropsychological Society, 13(6), 961-971.

Levine, B., Black, S.E., Cheung, G., Campbell, A., O’Toole, C., \& Schwartz, M.L. (2005). Gambling task performance in traumatic brain injury: Relationships to injury severity, atrophy, lesion location, and cognitive and psychosocial outcome. Cognitive and Behavioral Neurology, 18, 45-54.

MacPherson, S.E., Phillips, L.H., Della Sala, S., \& Cantagallo, A. (2009). Iowa Gambling Task impairment is not specific to ventromedial prefrontal lesions. Clinical Neuropsychologist, 23(3), 510-522.

Milders, M., Ietswaart, M., Crawford, J.R., \& Currie, D. (2008). Social behavior following traumatic brain injury and its association with emotion recognition, understanding of intentions, and cognitive flexibility. Journal of the International Neuropsychological Society, 14, 318-326.

Pawlowski, J., Remor, E., Parente, M.A.P., Salles, J.F., Fonseca, R.P., \& Bandeira, D.R. (2012). The influence of reading and writing habits associated with education on the neuropsychological performance of Brazilian adults. Reading and Writing, 25(9), 1-15.

Periáñez, J.A., Ríos-Lago, M., Rodríguez-Sánchez, J.M., Adrover-Roig, D., Sánchez-Cubillo, I., Crespo-Facorro, B., ... Barceló, F. (2007). Trail Making Test in traumatic brain injury, schizophrenia, and normal ageing: Sample comparisons and normative data. Archives of Clinical Neuropsychology, 22, 433-447.

Perlstein, W.M., Larson, M.J., Dotson, V.M., \& Kelly, K.G. (2006). Temporal dissociation of components of cognitive control 
dysfunction in severe TBI: ERP and the cued-Stroop task. Neuropsychologia, 44(2), 260-274.

Rao, V., \& Lyketsos, C. (2000). Neuropsychiatric sequelae of traumatic brain injury. Psychosomatics, 41(2), 95-103.

Sánchez-Cubillo, L., Periáñez, J.A., Adrover-Roig, D., RodríguezSánchez, J.M., Ríos-Lago, M., Tirapu, J., \& Barceló, F. (2009). Construct validity of the Trail Making Test: Role of task-switching, working memory, inhibition/interference control, and visuomotor abilities. Journal of the International Neuropsychological Society, $15,438-450$.

Schneider-Bakos, D., Denburg, N., Fonseca, R.P., \& Parente, M.A.P. (2010). A cultural study on decision making: performance differences on the Iowa Gambling Task between select groups of Brazilians and Americans. Psychology \& Neuroscience, 3(1), 101-107.

Schneider, D.D.G., \& Parente, M.A.M.P. (2006). O desempenho de adultos jovens e idosos no Iowa Gambling Task: Um estudo sobre a tomada de decisão. Psicologia: Reflexão e Crítica, 19, 442-450.

Sigurdardottir, S., Jerstad, T., Andelic, N., Roe, C., \& Schanke, A.K. (2010). Olfatory dysfunction, gambling task performance and intracranial lesions after traumatic brain injury. Neuropsychology, 24(4), 504-513.

Taylor, L.A., Kreutzer, J.S., Demm, S.R., \& Meade, M.A. (2003). Traumatic brain injury and substance abuse: A review and analysis of the literature. Neuropsychological Rehabilitation, 13(1), 165-188.
Tirapu-Ustarroz, J., Garcia-Molina, A., Luna-Lario, P., Roig-Rovira, T., \& Pelegrin-Valero, C. (2008). Models of executive control and functions (I). Revista De Neurologia, 46(11), 684-692.

Van Noordt, S., \& Good, D. (2011). Mild head injury and sympathetic arousal: Investigating relations with decision-making and neuropsychological performance in university students. Brain Injury, 25, 707-716.

Verdejo-García, A., \& Bechara, A. (2010). Neuropsicología de las funciones ejecutivas. Psicothema, 22(2), 227-235.

War Department (1944). Army Individual Test Battery. Manual of directions and scoring. Washington, DC: War Department, Adjutant General's Office.

Whelan-Goodinson, R., Ponsford, J., Johnston, L., \& Grant, F. (2009). Psychiatric disorders following traumatic brain injury: Their nature and frequency. Journal Head Trauma Rehabilitation, 24(5), 324-332.

Wiederkehr, S., Barat, M., Dehail, P., de Seze, M., Lozes-Boudillon, S., \& Giroire, J.M. (2005). Decision making and executive function in severe traumatic brain injured patients: Validation of a decisionmaking task and correlated features. Revue de Neurologie (Paris), $161,201-210$

Zgaljardic, D.J., \& Temple, R.O. (2010). Neuropsychological Assessment Battery (NAB): Performance in a sample of patients with moderate-to-severe traumatic brain injury. Applied Neuropsychology, 17(4), 283-288. 